\title{
EL DERECHO OBSERVANDO A LOS EMBRIONES: EL CASO ARGENTINO
}

\author{
Santiago Gabriel Calise \\ Universidad de Buenos Aires - CONICET-IIGG, Argentina
}

\begin{abstract}
Resumen.- El trabajo que se presenta a continuación analiza cómo el sistema jurídico observa las problemáticas relacionadas con la manipulación de embriones en la Argentina. Para ello se recurrirá al análisis de algunas fuentes del derecho, como la legislación, la jurisprudencia y la doctrina, complementadas por los proyectos de ley presentados por el sistema político. La posición asumida, tanto por el derecho, como por la política, es clara: el embrión es persona desde el mismo momento de la fecundación. Esto significa que la investigación con embriones y, para algunos, las técnicas de fertilización in vitro, deberían estar prohibidas. Esto se debe a que, tales procedimientos, van en contra del derecho a la vida y la dignidad del embrión humano. Para reforzar esta postura, se recurre frecuentemente a metáforas que tienden a humanizar al embrión, asimilándolo a un niño, y condenando a los métodos de fertilización asistida como formas industriales y eugenésicas de generar seres humano.
\end{abstract}

Palabras clave.- Fertilización in vitro, metáfora, persona, derecho a la vida, crioconservación.

Abstract.- The following paper analyzes how the law system observes the problems related to embryo manipulation in Argentina. To do so, some sources of law, such as legislation, jurisprudence and doctrine, will be analyzed, as well as the law projects presented by the political system. The position assumed by law and politics is clear: the embryo is a person since fertilization. That means that embryo research, and for some people, in vitro fertilization, must be banned, as they violate the right to life and the human embryo dignity. In order to reinforce this opinion, there is the tendency to resort to humanizing metaphors, equating embryo and child, as well as reducing fertilization therapies to industrial and eugenic procedures.

Keywords.- In vitro fertilization, metaphor, person, right to life, cryopreservation.

\section{Introducción}

El siguiente trabajo se propone analizar los problemas que conlleva la manipulación de embriones desde el punto de vista del sistema jurídico. Para ello se examinará la legislación, la jurisprudencia y la doctrina, además de los proyectos de ley, elaborados en la Argentina. Se comenzará por repasar las investigaciones sociológicas relacionadas con el tema, para poder señalar las diferencias y similitudes con el caso argentino. A continuación se harán algunas aclaraciones teórico-metodológicas respecto de la selección del material analizado. Posteriormente, se pasará al análisis de algunos fallos que tocan el tema y a los proyectos de ley que intentan reglamentar esta temática, para luego revisar la doctrina jurídica. Aquí se analizarán, sobre todo, las justificaciones ético-jurídicas y las metáforas utilizadas por los juristas. Por último, se presentarán las conclusiones. 


\section{Estado de la situación}

La mayoría de los trabajos sociológicos de investigación sobre temas de genética han preferido abordar su objeto de estudio desde las opiniones vertidas por la prensa. Muchos de ellos eligieron estrategias cuantitativas, como el de Nisbet, Brossard y Kroepsch (2003), cuyo trabajo marca tres puntos fundamentales a partir de los cuales los diarios comenzaron a prestarle fuerte atención al problema de las células madre. Estos son: cuando el Congreso de los EEUU comienza a tratar el tema (año 2001); cuando el tema involucró directamente la ingeniería genética en humanos; y, por último, cuando ya pudo enmarcarse la cuestión en términos dramáticos. Numerosos estudios dan cuenta de problemas similares (ver [Kruvand y Hwang, 2007]; [Maeseele and Schuurman, 2008]; [Nisbet y Lewenstein, 2002].)

Otro análisis de opinión pública, en este caso, a nivel europeo (Pardo y Calvo, 2008), muestra que, de los nueve países analizados, sólo en dos (Austria y PoIonia), los encuestados se manifestaron claramente en contra de la experimentación con embriones sobrantes, aunque, sólo en uno (Dinamarca), es considerado como aceptable el hecho de crear embriones para investigar. En relación con esto, es nuevamente en Dinamarca y, por un margen muy pequeño, también en el Reino Unido, donde la gente piensa, mayoritariamente, que los embriones humanos no son más que un montón de células.

Sin embargo, los trabajos de análisis de la prensa escrita más interesantes sobre temas de genética son aquellos de índole cualitativa, como el de Calsamiglia y Van Dijk (2004), donde se toma como objeto de estudio al diario El País de España, y se analiza la forma en que el tema del genoma humano es vulgarizado. La atención, en este trabajo, se centra en las explicaciones, descripciones, reformulaciones y metáforas, necesarios en la popularización de un tema científico tan alejado de la visión del mundo del lego. En otro trabajo sobre la prensa escrita y la televisión realizado por Williams, Kitzinger y Henderson (2003), se analiza como la imagen del embrión es construida social, cultural y políticamente. Por un lado, las autoras destacan como la prensa monta el debate sobre las células madre oponiendo, por una parte, a científicos, políticos laboristas y pacientes, y, por la otra, a los voceros religiosos. Otro punto muy destacable del análisis es la reconstrucción de la discusión sobre la manipulación de embriones, y las estrategias visuales que utilizan las dos partes opuestas para sostener sus posiciones. De esta manera, el embrión es representado como una especie de aglutinamiento de células congeladas, parecidas a planetas flotando en el espacio. Mientras que unos resaltan la irrelevancia de su tamaño, otros tienden a atribuirles características similares a las de los niños, como su supuesta inocencia. Otras acusaciones cruzadas que se resaltan son las de los enfermos que podrían ser curados con el avance de las terapias con embriones, que introducen frases como "soy yo o un huevo", mientras que otros lanzan acusaciones de "canibalismo". Sin embargo, destacan las autoras:

Both, in part, draw their power from a deeply racialised notion of civilisation versus primitive barbarity, both leave the concept of progress unquestioned (2003: 806). 
Por último, cabe señalar cómo, dentro del debate, los problemas de género son completamente obliterados. Estas representaciones visuales, que muestran a los embriones como planetas flotando en el negro espacio, olvida de dónde provienen esas células, y deja de lado el debate sobre el consentimiento que deberían dar las mujeres para que se utilicen esas células, que fueron generadas por sus cuerpos.

Otro estudio de gran relevancia, también realizado en el Reino Unido, por la socióloga Sarah Parry (2003), analiza los debates parlamentarios y sus estrategias retóricas, sobre las leyes relacionadas con el uso de células madre y embriones. Aquí también se reconstruyen las posiciones asumidas por los bandos favorables u opositores, los argumentos y los discursos utilizados para justificar esas posiciones. Pero el estudio de los debates parlamentarios sobre el problema del embrión, en el Reino Unido, tiene como máxima referencia a los trabajos de Michael Mulkay (1993; 1994a; 1994b; 1995a; 1995b), donde se observan las estrategias retóricas de los grupos favorables a la utilización de embriones para experimentación científica, y los que eran contrarios. El debate llegó a plantearse, por parte de los partidarios de la ciencia, en términos de la ciencia contra la religión, la fe o creencia contra la razón, la acrítica repetición de dogmas contra la apreciación de una mente abierta, etc. (1995a) No obstante, señala el sociólogo, ambas posiciones fueron claramente dogmáticas y ninguna estuvo dispuesta a evaluar cualquier argumento que no fuese compatible con su visión de los hechos. Pero, además, a final de cuentas, el apoyo a la investigación con embriones se basó, sobre todo, en la fe en la benevolencia de la ciencia. Respecto de este mismo país, los análisis de Peter Glasner (2005) desarrollan el tema del primer banco de células madre y la economía moral que su implementación implica.

Por otra parte, Marta Kirajczyk (1999) también se dedicó al análisis de los debates parlamentarios sobre las leyes concernientes a la investigación con embriones en Holanda. En este caso, las posiciones eran mucho más ambiguas y no había un fuerte lobby pro-investigación, como en Gran Bretaña. Sin embargo, es de destacar como, pese a que el debate fue llevado adelante, prevalentemente, por mujeres, solamente algunos pequeños partidos de izquierda alertaron sobre el riesgo que podrían correr las mujeres en convertirse en proveedoras de óvulos para la investigación. En el trabajo de Barbara McCloskey (2002) se analiza la controvertida historia de la investigación con células madre en los Estados Unidos, mostrándose el pasaje de la prohibición de utilizar fondos federales para tales pesquisas, impuesta por el presidente Clinton, en 1996, hacia la ambivalente decisión del presidente Bush (2001), de permitir la investigación, pero prohibiendo utilizar tales fondos para destruir embriones.

Desde una perspectiva diferente, una investigación antropológica en las clínicas de fertilización en Dinamarca (Svendsen y Koch, 2008), muestra como se construyen, en la cotidianeidad de las prácticas, categorías tan importantes para la ley, como la de embrión sobrante o supernumerario. En este sentido, las clínicas tienden a clasificar a los embriones "feos" como sobrantes, pasibles de ser donados para investigación o, directamente, descartados. Por otro lado, los investigadores se lamentan de esta situación, debido a que la escasa cali- 
dad del material recibido se ha convertido en un cuello de botella para la investigación. Esto significa que las clasificaciones no obedecen, en ningún momento, a criterios ontológicos. En relación con esto es que, también la categoría de "embrión supernumerario" depende del criterio del terapista, ya que es él quien decide cuál es el número de embriones que considere suficiente. Pero además, se presenta el problema de cómo y cuándo proponer a la pareja bajo tratamiento que done sus embriones "sobrantes".

\section{Metodología}

Para la realización de esta investigación se ha decidido recurrir a las fuentes del derecho, que se definen como "el conjunto de factores o elementos que ejercen influencia en la formación, por parte del juez de las reglas en las que éste basa su decisión; con el agregado de que esta influencia puede variar: desde aquellas 'fuentes' que proporcionan al juez una norma jurídica ya elaborada que simplemente tiene que aceptar, hasta aquellas otras que no le ofrecen nada más que ideas e inspiración para que el propio juez formule la norma que necesita." (Ross, 1997: 107). De esta manera, se pueden reconocer diversas fuentes sobre la base de su grado de objetivación, que varía desde la regla ya formulada, lista para su aplicación, hasta la provisión de un cierto material necesitado de un proceso de transformación por parte del juez.

En consecuencia, Ross propone clasificar las fuentes del derecho en tres categorías: las fuentes completamente objetivadas (legislación); las fuentes parcialmente objetivadas (costumbre y precedente); las fuentes no objetivadas (la "razón" o "cultura"). El citado planteo de Ross trata el problema a nivel general, pero debe recordarse que cada instancia del derecho tiene sus propias fuentes, en este sentido, las fuentes del derecho civil no tienen porqué coincidir con las fuentes del derecho penal. Al tratarse, en este trabajo, mayormente, de un caso de derecho penal, se recurrirá a las fuentes del derecho penal, que Soler (1987) clasifica como: la ley, la costumbre, la doctrina, y la jurisprudencia. Aquí se tomarán las fuentes escritas, como la legislación, la jurisprudencia y la doctrina, que tienen la ventaja, respecto de la costumbre y la cultura, de estar ya plasmadas objetivamente y publicadas, lo cual implica un filtro interno al mismo sistema jurídico. Otra virtud de la utilización de estas fuentes es que son un discurso interno al mismo sistema, y no es algo generado para responder a interrogantes externos formulados por el investigador, con lo cual no se añade ni se quita nada de lo generado por el mismo.

Desde el punto de vista de la teoría de sistemas, el concepto de fuentes del derecho debe ser entendido como una doctrina que elabora el propio sistema jurídico al autoobservarse (Luhmann, 1993; 2006). Este concepto permite que se identifique de manera simple cuál es el derecho vigente, dejando de lado cualquier pregunta acerca de la naturaleza o la esencia del derecho, o de la delimitación entre derecho y costumbre, o entre derecho y moral. Sin embargo, señala Luhmann, esta categoría funciona solamente si no se pregunta por el "de dónde" y el "hacia dónde", que implica la metáfora de la fuente. Pero, al mismo tiempo, el concepto trabaja induciendo a que se busque permanentemente una referencia externa (el pueblo, la costumbre, la autoridad institucio- 
nal, etc.). No obstante, la doctrina de las fuentes del derecho tiene la virtud de, al asimetrizar la relación entre legislación y jurisprudencia, evitar la circularidad resultante de admitir que los tribunales crearían el derecho que ellos mismos aplican. Por el contrario, la decisión del tribunal serviría como principio de conocimiento del derecho. Además, la ampliación de este concepto para incluir en él la jurisprudencia, permite al derecho positivo deshacerse de la relación con la fuente externa, consintiendo que esta externalidad -artificial y contingente-, aparezca a la autoobservación del sistema como algo natural y necesario.

Entonces, esta doctrina de las fuentes del derecho funcionaría como símbolo de la unidad del sistema, solucionando las dudas puntuales que pueden surgir sobre si el derecho es válido como derecho. Sin embargo, la forma jerárquica que asume esta categoría -correspondiente a un ordenamiento societal estratificado-, es incapaz de dar una respuesta respecto de la unidad de la propia diferencia que la constituye. En este sentido, la unidad solamente puede presentarse como la diferencia de rango. Es por esto que, desde la teoría de sistemas autopoiéticos, autorreferenciales y clausurados en la operación, se prefiere sustituir el concepto de fuentes del derecho por el de validez -en cuanto unidad de la diferencia entre válido / no-válido. Por un lado, el símbolo de validez permite disolver la ambigüedad de la referencia externa que implica la metáfora de la fuente, entendiéndolo como un valor propio (Eigenwert) del sistema, surgido de la recursividad de las operaciones de este mismo. Por consiguiente, todo derecho es siempre derecho vigente, ya que el derecho no vigente no sería derecho. Por otra parte, de esta manera, se traslada el problema hacia el nivel operativo, considerando al símbolo de validez como una transición de una situación de derecho hacia otras. Por último, cabe entender a las leyes, jurisprudencia y doctrina, en cuanto que criterios de decisión utilizados por los tribunales, como los programas del sistema mismo.

En el trabajo se analizarán las fuentes del derecho en cuanto el problema de investigación es de naturaleza comunicativa, o sea que se debe introducir en los entramados de comunicación para lograr observar las observaciones de segundo orden que hacen nuestros observados sobre las propias observaciones de primer orden. Que se tomen discursos firmados por individuos concretos como centro de observación, no significa que se quiera rescatar las perspectivas idiosincrásicas de sus autores, sino que se los interpela en calidad de usuarios de los medios observacionales e interpretativos disponibles en el repertorio de sus comunidades. Debido a ello, cuando se trata de muestras, en la observación de segundo orden son decididamente intencionadas, respondiendo a criterios socioestructurales delimitados por el investigador. (Arnold, 1998) El problema frente al que se topó, a la hora de determinar el universo, fue que no existe un lugar físico que tenga en su poder todos los artículos de doctrina jurídica, ni tampoco existe un registro que unifique y dé cuenta de todos los artículos de doctrina existentes. Como consecuencia, este inconveniente nos obliga a no poder contemplar todo el universo del cual extraer una muestra. Sin embargo, se ha tenido acceso a los artículos publicados por las principales editoriales. De la editorial Abeledo Perrot se han seleccionado 8 artículos, de la editorial La Ley, 8; de El Derecho, se cuentan $10^{1}$. También se revisaron las

\footnotetext{
${ }^{1}$ En el anexo al final del trabajo se detallan los títulos de los trabajo estudiados.
} 
bases de datos de otras editoriales, donde no se encontró material de relevancia para el trabajo.

En cuanto a la jurisprudencia, se cuenta con tres fallos que tocan el tema. Por último, respecto de la legislación, no hay leyes que regulen el tema, pero sí numerosos proyectos de ley (8), que serán, también, objeto de análisis. El lector podría preguntarse por qué no analizar los debates parlamentarios de los mencionados proyectos, siguiendo la pequeña tradición que se fue creando en la sociología internacional. Sin embargo, esta omisión no se debe alguna decisión teórico-metodológica o a la pereza del autor, sino, más bien, a su práctica inexistencia ${ }^{2}$. Las poquísimas referencias marginales al problema del embrión son tan esporádicas, que se hacen inanalizables.

\section{El inicio de la vida en la jurisprudencia}

En el artículo 63 del Código Civil se dice que es persona por nacer, aquella que, aun no habiendo nacido, se encuentra ya en el seno materno, mientras que en el artículo 70 se sostiene que la existencia de la persona comienza desde la concepción en el seno materno. Por su parte, en la Convención Americana sobre Derechos Humanos -que posee jerarquía constitucional- en el artículo 4 inciso 1, se afirma el derecho a la vida desde la concepción. El problema aquí es saber en qué momento se da la concepción. A continuación se presentarán tres fallos que resuelven el problema de manera idéntica, aunque las temáticas tratadas sean diferentes.

En el primero, "Rabinovich, Ricardo David s/medidas precautorias (R., R. D.)", llegado a la Cámara Nacional de Apelaciones en lo Civil $^{3}$, llamó a que intervenga el Ministerio Pupilar, para que se protejan "las vidas y/o salud física y/o psíquica" de un "conjunto incierto pero determinable de incapaces", ya que, en la Ciudad de Buenos Aires, se practican técnicas de congelamiento de personas por nacer, con diversas finalidades y fuera de todo control por parte de aquel Ministerio y/o de los jueces competentes ${ }^{4}$. Respecto del estatuto del embrión, se estableció que:

en nuestro ordenamiento legal y constitucional todo ser humano es persona, y lo es desde su concepción, sea en el seno materno o fuera de él; y a partir de entonces, consecuentemente, es titular de derechos, entre ellos y ante todo de los derechos a la vida y a la integridad física y psíquica. Tal la premisa desde la cual debe examinarse la situación planteada en el caso "sub iudice".

\footnotetext{
${ }^{2}$ El lector curioso puede verificar por sus propios medios tales afirmaciones, visitando las siguientes direcciones: $\quad$ http://www.senado.gov.ar/web/taqui/cuerpo1.php $\quad$ y http://www.diputados.gov.ar, donde se pueden revisar los debates parlamentarios.
}

3 Publicado en: LA LEY 2001-C, 824 - Colección de Análisis Jurisprudencial Derecho Civil Parte General - Director: José W. Tobías, Editorial LA LEY, 2003, 33, con nota de José W. Tobías; Gonzalo Lavalle.

${ }^{4}$ Como se comenta en la doctrina (2000-AP-6), tal recurso ha sido aceptado sobre la base de la "admisibilidad del reclamante como interesado difuso", pudiéndose argumentar la existencia de un "daño a la especie humana". 
VII. Ello supuesto, es claro que todas aquellas teorías que de diversos modos sólo reconocen al ser humano la condición de persona en etapas posteriores a su concepción, resultan incompatibles con dicho ordenamiento.

De esta manera, se equipara concepción con fertilización, sosteniéndose que se puede hablar ya de "persona", cuando el espermatozoide y el óvulo se fusionan. Pero, además de esto, excediendo sus facultades, el tribunal ordenó que se realizara un censo de "embriones no implantados y ovocitos pronucleados", existentes en la Ciudad de Buenos Aires, agregando que quedaba prohibida "toda acción sobre los mencionados embriones y ovocitos -sea por parte de los dadores de los gametos, sea por parte de las instituciones o profesionales actuantes- que implique su destrucción o experimentación." Por consiguiente, en este caso, el tribunal habría virtualmente legislado sobre el uso experimental de embriones ${ }^{5}$. Para algunos juristas, las medidas tomadas por el tribunal no están orientadas a ordenar la actividad, sino, por el contrario, a "entorpecerla mediante trabas que dificulten, hasta hacer imposible, la aplicación de las NTRH [nuevas técnicas de reproducción humana]" (Arribere, 2005). Al mismo tiempo, en el citado texto, se critica la "aplicación literal de la normativa del Código Civil sancionado hace más de cien años atrás", que permite categorizar a ovocitos pronucleados y preembriones criopreservados solamente como personas o como cosas ${ }^{6}$. Frente a estas acusaciones, algún otro puede argumentar que la intención de disociar al nasciturus respecto de la persona, "sólo obedecería a la necesidad de justificar, biológicamente, la manipulación y experimentación de embriones humanos, como también legitimar las prácticas abortivas." (Errázquin, 2008)

Un segundo antecedente de suma importancia fue un caso que arribó hasta la Corte Suprema, del año $2002^{7}$, referido a un amparo interpuesto por la asociación "Portal de Belén", en relación con la llamada "píldora del día después", donde se terminó fallando a favor de la prohibición de tal medicamento, al ser considerado abortivo. Yendo al punto concerniente a la cuestión de la concep-

\footnotetext{
${ }^{5}$ Pese al mandato judicial, el censo no pudo llevarse a cabo, por las numerosas negativas que presentaron las instituciones a ser encuestadas. Ante esta situación, quien, a la postre, sería designado como "tutor especial" de los embriones congelados y ovocitos pronucleados se pregunta: "¿Qué hay atrás de esto? ¿Por qué ni siquiera se informa cuántos son los embriones congelados? ¿A qué se teme tanto? Recientemente, los diarios anunciaron experimentos concretados o planeados en otros países, incluso Brasil, con embriones humanos, con fines terapéuticos (pero también industriales, cosméticos, etc.) ¿Ha metido este fallo el dedo en una llaga inesperada? Espero sinceramente que no, pero me confieso asustado" (Rabinovich-Berkman, 2005)

${ }^{6}$ Nótese como, en este texto, que manifiesta una clara oposición a la lectura dominante del fenómeno, se utiliza el vocablo "preembrión", mientras que la postura prohibicionista indica continuamente que ese término pretende denominar algo inexistente (Perrino, 2006), ya que no hay etapas de diferente naturaleza en el desarrollo embrionario (Ferrer, 1995)

7 Publicado en: DJ 2002-1, 664 - LA LEY 2002-B, 520 - LA LEY 2002-C, 487, con nota de Germán J. Bidart Campos; LA LEY 2002-C, 697, con nota de Luis Guillermo Blanco; DJ 20022, 13, con nota de Jorge L. Manzini; Colección de Análisis Jurisprudencial Elems. de Derecho Administrativo - Julio Rodolfo Comadira, 380 - Colección de Análisis Jurisprudencial Derecho Constitucional - Director: Alberto Ricardo Dalla Via, Editorial LA LEY 2002, 635, con nota de Marcela I. Basterra;
}

Cita Fallos Corte: 325:292 
ción, los jueces volvieron a asegurar que esta última tendría lugar en el momento de la fertilización.

Por último, se encuentra el caso, presentado ante la Cámara Federal de Apelaciones de Mar del Plata (L.H.A. y otra contra IOMA y otra s / amparo) ${ }^{8}$ donde se condenaba a las obras sociales a que cubran "los tratamientos de fertilización asistida necesarios, a fin de permitir a la pareja impetrante tener un nuevo hijo que resulte histocompatible con su hermano enfermo, a través del sistema de fertilización asistida con selección de un embrión no portador de la enfermedad granulomatosa crónica y que dicho embrión sea histoidéntico a su hijo, para intentar su cura vía trasplante de las células progenitoras y de las que requiera en el futuro, según la pertinente indicación médica, para lograr la cura de la enfermedad que hoy padece el niño." El problema no fue encontrado en la instrumentalización del niño por nacer, que debería servir para curar a su hermano, sino en la pregunta por el qué hacer con los embriones no utilizados, ya que "su 'descarte' vulnera el derecho a la vida de los mismos, y su utilización en el campo experimental conlleva un atropello contra la dignidad de la persona humana." Por lo tanto, resuelven los magistrados:

En caso de existir 'embriones sobrantes' o 'no transferidos' luego de la terapia ordenada, se debe proceder a la inmediata crioconservación de los mismos hasta que exista una regulación legal que ampare y proteja sus derechos inherentes a la condición humana que ostentan, o hasta que pudiera existir una decisión judicial que permitiera la adopción prenatal si ello fuese considerado factible por el órgano judicial interviniente y se dieran los demás requisitos exigidos por la legislación argentina específica y aplicable al caso. (Del voto del Dr. Tazza, al que adhieren los Dres. Ferro y Comparato - mayoría)

Para los funcionarios, los embriones deben ser considerados personas, con derechos y obligaciones, puesto que, para la legislación argentina, "la existencia de la persona comienza desde el momento de la concepción, sea en el seno materno o fuera de él".

Respecto de esta sentencia, las posiciones de la doctrina no son unánimes. Algunos señalan que la decisión es inaceptable para nuestro ordenamiento jurídico, pues pretende arribar a una solución "humana" y jurídica imposible de lograr: intentar salvar la vida del enfermo y a la vez proteger la vida e integridad de todos los embriones producidos para curarlo. Resulta contradictoria la postulación de la protección de la vida desde la concepción y a la vez la autorización de un procedimiento que conlleva la muerte de la inmensa mayoría o la totalidad de los seres humanos que declara proteger. (Quintana, 2009)

Otros, califican directamente de "inmoral" a este tipo de procedimientos, ya que "crear un ser para ser usado en orden a sanar a otro, por medio de la muerte prevista con dolo eventual, al menos, de sus hermanos y la criopreservación de otros muchos hermanos." (Basset, 2009) Pero también, en relación con este fallo, se critica la opción de congelar por tiempo indefinido a los embriones no utilizados, ya que el destino de estos permanecerá incierto. Además de que el

\footnotetext{
${ }^{8}$ Publicado en: Microjuris-JU-M-41413-AR.
} 
tiempo de conservación criogénico exitoso más largo que se conoce es de dos años (Nallar, 2009). Sin embargo, tal interpretación derivaría en la prohibición completa de la fecundación in vitro, técnica que parece mundialmente aceptada. Por otra parte, posiciones más moderadas afirman compartir "el criterio seguido por los camaristas y valoramos las pautas expuestas en miras a la protección de los embriones crioconservados." (Krasnow, 2009)

\section{El embrión en los proyectos de ley}

Como se señalaba anteriormente, la Argentina no cuenta con una ley que regule detalladamente las prácticas de fecundación asistida en sus diversas variantes, no obstante, se han presentado varios proyectos de ley en el Congreso. En general, todos ellos siguen las líneas trazadas en los fallos anteriores, o sea, en todos los casos donde se hace mención puntual del inicio de la vida, se sostiene que ésta comienza con la penetración del espermatozoide en el óvulo (4451-D-2001; 3976-D-2003; 3518-S-2006; 1437-D-2008 ${ }^{9}$ ). Sin embargo, acorde con uno de los comentarios doctrinales antes referidos, la política ha comenzado a inclinarse por la prohibición de la crioconservación (4451-D-2001; 3518-S-2006; 0170-S-2008; 1437-D-2008), pese a que se planteen algunas excepciones, como en caso de muerte de la madre, o si la madre, en el momento del procedimiento, no se encuentre en condiciones de salud adecuadas. Esta línea prohibicionista, que propone también penas para quienes crioconserven embriones, parece ir ganando, paradójicamente, más espacio en la opinión de los legisladores, quienes elaboran, cada vez, proyectos más restrictivos. Restricciones como la anteriormente referida, pueden tener el propósito encubierto de obstaculizar al máximo la fertilización asistida, limitando las posibilidades del médico o haciendo encarecer los tratamientos, de manera que el paciente termine por desistir, de antemano, del procedimiento. Lo anteriormente referido se ve reforzado cuando se encuentra en ciertos proyectos que, con el fin de no crioconservar embriones, se restringe a tres (1957-S-2006; 3518-S2006; 0170-S-2008) o a uno (1437-D-2008) el número de óvulos pasibles de ser inseminados. De tener que operar bajo estas limitaciones, los costos aumentarán y también la efectividad de la técnica, si es que prospera la propuesta de transferir un solo embrión por vez.

Por otra parte, relacionado con la cuestión de la criopreservación, aparece un tema mencionado en el último de los fallos analizados, que es el de la adopción de embriones. Uno de los proyectos propone que se notifique a la pareja que donó el material genético para producir el embrión, dentro de un plazo de 30 días, para que presten su consentimiento para dar en adopción a tal embrión. Al vencer tal plazo, el juez tendrá la facultad de dar en adopción a tal ser "como si se tratara de un menor abandonado" (4451-D-2001). Otros proponen agregar al artículo 313 del Código Civil la posibilidad de adoptar "una persona por nacer que se encuentra fuera del útero", a condición de que sea implantada dentro de los noventa días (1957-S-2006). Un último proyecto propone que los embriones

\footnotetext{
${ }^{9}$ Todos los proyectos referidos en este trabajo, pueden ser hallados en el sitio web del Congreso de la Nación: http://www.congreso.gov.ar/
} 
existentes al momento de promulgarse la ley se vuelvan disponibles para las mujeres que deseen implantárselos (1437-D-2008). Sin embargo, en otros esbozos, aparece la prohibición de la adopción de tales embriones (1070-S2008). Naturalmente, estas ideas presuponen todas ellas, que el embrión es una persona y sus "padres" no tendrían completa libertad de disponer de él como una cosa. En este sentido, como era de suponerse, tales proyectos pretenden prohibir todo tipo de experimentación con embriones (4451-D-2001; 3518-S-2006; 1437-D-2008), aunque también, tal como se ha visto en el primer fallo analizado, se ha propuesto conformar la figura del "tutor general de los embriones y ovocitos pronucleados humanos", que tendría la función de "velar por el respeto de la vida, la integridad física y la dignidad de sus defendidos, y es parte esencial en todos los juicios que los involucren." (4580-S-2006)

Para concluir con este breve tratamiento de los proyectos de ley, se puede destacar que, en las fundamentaciones otorgadas por los legisladores, se hace referencia frecuente a la situación anómica propia de la Argentina (3518-S-06; 4580-S-06; 1437-D-08). En uno de ellos, se llega a comparar a los embriones con los desaparecidos por la dictadura, de la siguiente manera:

Señor presidente, treinta mil fueron los desaparecidos que trajo el régimen militar a nuestra patria. Justificadamente se crearon, para investigar su destino y resguardar los derechos de sus causahabientes, cargos y oficinas públicos. Aquellos compatriotas, desgraciadamente, ya han muerto...

Pero ahora hay, señor presidente, otros treinta mil seres humanos (curiosa y paradójica coincidencia numérica) que, conservando en elocuente silencio su esperanza de nacer, esperan ser traídos a la luz. Ellos aún pueden -y debenvivir. Y merecen, por lo menos, idénticos esfuerzos. (4580-s-06)

De esta comparación podría deducirse que el autor estaría dando a entender que se está perpetrando una especie de genocidio de embriones. Sin embargo, ¿esto implica que el gobierno actual se esté comportando como la dictadura militar? La relación entre totalitarismo y este tipo de prácticas, en ciertas ocasiones, calificadas de "eugenésicas", se volverá a encontrar al tratar las metáforas elaboradas por la doctrina.

\section{El inicio de la vida para la doctrina jurídica}

En el sistema jurídico continental, el derecho trabaja con una división binaria entre persona y cosa (Hennette-Vauchez, 2008). Algo diferente sucede en los sistemas de Common Law, como los Estados Unidos. Respecto del problema del inicio de la vida del embrión, en los varios Estados de ese país, se asumieron tres posiciones diferentes (Parise, 2007). La primera es aquella a la que se hacía referencia previamente, o sea, la que interpreta que el embrión humano es persona y está biológicamente vivo y es genéticamente uno. La segunda interpretación lo entiende como una cosa,

un apéndice del cuerpo humano, un tejido extracorporal, extraído del cuerpo de los donantes. Por ende, el embrión humano es una cosa susceptible de apre- 
hensión y quienes apoyan esta posición entienden que puede ser algo sujeto a propiedad, y por ende, sujeto al dominio de la persona.

Por consiguiente, según este punto de vista, los donantes podrían disponer del embrión a su voluntad. La última posición entiende que el embrión no es ni persona, ni cosa, pero es susceptible de un respeto especial. En este sentido, no se lo podría asimilar a un tejido humano cualquiera o extracorpóreo, pero tampoco a una persona, debido a su escasísimo desarrollo biológico. Por último, se argumenta que la protección debería incrementarse al acercarse al período fetal.

En la Argentina la posición es clara y no se han registrado aun contradicciones entre la jurisprudencia. Así como en la jurisprudencia y los proyectos de ley, la equiparación entre fecundación, concepción y nacimiento de una persona, también se encuentra de manera casi completamente unánime en la doctrina (Cocca, 1984) (Ferrer, 1995) (Barra, 1996) (Blanco, 1997) (Madrid Ramírez, 2001) (Rabinovich-Berkman, 2005) (Barbieri, 2005) (Errázquin, 2005) (Perrino, 2006) (Errázquin, 2006) (Parise, 2007) (Basset, 2008) (Andújar de Zamora, 2008) (Nallar, 2009) (Rosales, 2009). Algunos insisten en la unicidad propia del embrión (Nallar, 2009), porque este nuevo ser tiene un genoma diferente (Ferrer, 1995) (Basset, 2008), o porque es ya un ser "en sí mismo", diferente de una célula, que tiene individualidad, pero no "ensimismidad" (Barra, 1996). Estos hechos son vistos como científicamente probados (Nallar, 2009) (Errázquin, 2005), como algo que no admite dudas (Perrino, 2006) (Basset, 2008), o que no se discute (Barbieri, 2005). Este sustento científico se basa en la imposibilidad de distinguir etapas o saltos evolutivos que determinen el comienzo de la vida, de lo cual se deriva que, desde el primer instante -el de la fecundación-, el ser humano es tal. Ante semejante uniformidad de criterios, sólo una voz se ha levantado para señalar que, si bien la opinión de que el embrión es una persona es respetable, "no es científica desde ningún punto de vista" (Rosales, 2009). Sin embargo, embrollarse en esta polémica, ajena al derecho en sí, podría derivar en infinitos debates biológico-filosóficos, de difícil resolución. Más simplemente, un autor, un tanto cínicamente señala que "si los embriones y ovocitos pronucleados son o no personas, puede debatirse en los ámbitos académicos, pero no en un expediente, cuyo fallo firme dice, en forma contundente, que lo son."10 (Rabinovich-Berkman, 2005) Esto significa que los datos científicos son un detalle menor, ya que lo que verdaderamente le interesa al sistema es su propia autopoiesis, y la interpretación aceptada en la jurisprudencia y en la doctrina -secundariamente-, respecto de los artículos ya mencionados del Código Civil.

Esta posición trae aparejado pensar que la fertilización in vitro, debido a su baja efectividad, es violatoria del derecho a la vida, ya que implica el sacrificio de numerosos embriones, que no llegarán a anidarse y otros que morirán producto de la crioconservación (Casanova, 2005) (Quintana, 2009). En este sentido, algunos afirman que la tutela de la vida es un deber absoluto, por lo cual "el respeto del valor de la vida humana sólo puede ceder al valor de otra vida

\footnotetext{
10 Tal comentario hace referencia al primero de los fallos estudiados, donde se ordenaba que se realice un censo de todos los embriones congelados. Tal afirmación del autor venía a colación de la negativa de los laboratorios a proveer la información demandada por el Estado.
} 
humana amenazada por la primera" (Barra, 1996). Relacionado con esto, algunos llegan a abogar por el derecho a nacer que tienen todos los embriones, por lo cual no se los podría tener congelados por un tiempo indefinido (RabinovichBerkman, 2005).

\section{Las metáforas sobre el embrión}

En el clásico Metaphors we live by (Lakoff y Johnson, 2003), se concibe a la metáfora como una forma de entender y experimentar un tipo de cosas en términos de otras. De esta manera, se puede comprender un aspecto de un concepto en términos de otro, ocultando las demás propiedades. En un libro escrito junto a Mark Turner años más tarde (1989), la metáfora es entendida como una proyección. Esta proyección asume cuatro formas: los casilleros, las relaciones, las propiedades y los saberes. Estas cuatro características del esquema semántico-fuente se proyectan sobre sus equivalentes en el campo semántico-meta ${ }^{11}$. Para los fines del análisis, se utilizará esta segunda propuesta teórico-metodológica.

El análisis de la doctrina, muestra que hay tres tipos metáforas recurrentes. Unas, que podrían ser llamadas de la "familiaridad", nombran al embrión como "niño" (Rabinovich-Berkman, 2005) y trata a los embriones, entre ellos, como "hermanos" (Basset, 2009) (Quintana, 2009). Más frecuentes aun son las metáforas que asimilan a los métodos de fertilización asistida con la producción industrial como: "Este 'encargar' no a la cigüeña, sino al médico que les 'fabrique' un hijo viola por lo menos cuatro de los derechos básicos de las personas" (Casanova, 2005); "el embrión es tratado como un objeto de producción sometido a un proceso de tipo eminentemente técnico-instrumental" (Quintana, 2009); "en la manipulación de embriones humanos, y en general, de la vida humana, el interés se va generalizando y se acerca la manufactura industrial" (Cocca, 1994). Por último, se encuentran las figuras relacionadas con el eugenismo: "en la etapa inmediatamente subsiguiente a la fecundación, con criterio eugenésico, se seleccionan los 'mejores' embriones, y se implantan tres o cuatro. La idea es darwiniana: cuantos más sean los embriones, más idóneos serán los escogidos" (Rabinovich-Berkman, 2005); "el biólogo se convierte en un 'hominicultor' dedicado a la creación de una nueva raza humana superior" (Ferrer, 1995).

El primer conjunto de metáforas trabaja en pos de la estrategia retórica de "humanizar" al embrión, tratándolo como una especie de pequeñísimo bebé, que tiene "hermanos", como los niños verdaderamente ya nacidos. El cuadro que se propone a continuación, presenta una forma de observar la proyección semántica que implican estas metáforas.

${ }^{11}$ También se puede revisar el libro Metáforas en uso (Mariana Di Stefano (coord.), 2006), donde se presentan ejemplos de la utilización de la teoría de Lakoff y Turner. 


\section{Cuadro 1. Metáforas de la "familiaridad"}

\begin{tabular}{|c|c|}
\hline $\begin{array}{l}\text { Elementos de la pro- } \\
\text { yección de la metá- } \\
\text { fora }\end{array}$ & Infantes (campo fuente) \\
\hline Casilleros & $\begin{array}{ll}\text { 1. } & \text { Características físicas } \\
\text { 2. } & \text { Características psíquicas } \\
\text { 3. } & \text { Relación con los adultos }\end{array}$ \\
\hline Propiedades & $\begin{array}{l}\text { 1. Características físicas: sus cuerpos son peque- } \\
\text { ños y necesitan tiempo para desarrollar sus miembros } \\
\text { y adquirir ciertas habilidades } \\
\text { 2. Características psíquicas: son inocentes y bue- } \\
\text { nos. Carecen de maldad. } \\
\text { 3. Relación con los adultos: necesitan de la protec- } \\
\text { ción de los padres, ya que no pueden autoabastecerse. }\end{array}$ \\
\hline Relaciones & $\begin{array}{l}\text { Debido a que todavía no han llegado a desarrollarse } \\
\text { física y psíquicamente, los niños necesitan de los cui- } \\
\text { dados y la atención de sus padres y familiares cerca- } \\
\text { nos. }\end{array}$ \\
\hline Saberes & $\begin{array}{l}\text { 1. La niñez es una etapa del desarrollo evolutivo } \\
\text { físico y psíquico de todo ser humano. } \\
2 \text {. En la cultura occidental (omitiendo los desarro- } \\
\text { llos de la teoría psicoanalítica), el niño es asociado a la } \\
\text { pureza, la inocencia, la ignorancia y la bondad. Sería la } \\
\text { sociedad la que vendría a corromper ese estado origi- } \\
\text { nario. }\end{array}$ \\
\hline
\end{tabular}

\begin{tabular}{|c|c|}
\hline $\begin{array}{l}\text { Propiedades proyec- } \\
\text { tadas de la infancia }\end{array}$ & $\begin{array}{l}\text { 1. } \quad \text { Características físicas: sus cuerpos son peque- } \\
\text { ños y poco desarrollados } \\
\text { 2. Características psíquicas: son, esencialmente, } \\
\text { inocentes. } \\
3 . \quad \text { Relación con los adultos: necesitan ser cuidados }\end{array}$ \\
\hline $\begin{array}{l}\text { Propiedades que se } \\
\text { le asignan al em- } \\
\text { brión }\end{array}$ & $\begin{array}{l}\text { 1. Características físicas: se encuentran en la eta- } \\
\text { pa de menor desarrollo físico, pero, contienen en sí, } \\
\text { todas las potencialidades para desarrollar su cuerpo, } \\
\text { según su código genético único. } \\
\text { 2. Características psíquicas: son inocentes y no } \\
\text { merecen ser maltratados, despedazados para ser in- } \\
\text { vestigados, ser dejados morir o congelados a bajísi- } \\
\text { mas temperaturas. } \\
\text { 3. Relación con los adultos: los padres deben cui- } \\
\text { dar de ellos y no permitir las manipulaciones a las cua- } \\
\text { les la ciencia médica pretende someterlos. }\end{array}$ \\
\hline
\end{tabular}

Por lo tanto, lo que se pretende es asimilar al embrión, aun al embrión de un día de edad, a un niño, en cuanto que, si uno piensa en un cigoto como un infante, claramente sería un crimen hacerlo morir, congelarlo o experimentar con él. La siguiente frase es un claro ejemplo de ello: 
El embrión por sí mismo modula su metabolismo en función de los sustratos que le proporciona el ambiente materno para su desarrollo, del mismo modo que lo hacemos los seres humanos ya nacidos ${ }^{12}$. (Errázquin, 2005)

En principio, el texto apela directamente al lector, involucrándolo en el colectivo "seres humanos ya nacidos", haciendo imposible que uno pueda evadirse de tal condición. Por otro lado, la autora habla de "comunicación bioquímica", "comunicación celular" o "sistema de comunicación materno-embrionario", que profundizan esta "humanización" del embrión, al presentar como un hecho profundamente humano, social y cotidiano, algo que, en realidad, es un conjunto de procesos químicos independientes de la conciencia o de la sociedad.

Los otros dos grupos de metáforas operan presentando a las técnicas de fertilización asistida como algo negativo, artificial y deshumanizante. Al tratar a estos métodos contra la infertilidad como una forma industrializada de producir hijos, lo que se condena es la desacralización que conllevan estas técnicas, que se inmiscuyen en lo más sagrado que posee el ser humano, que es la vida. De esta manera, la ciencia ha logrado arribar hasta ese rincón que todavía, hace unas cuantas décadas, parecía intocable, el último refugio de lo sacro. Es por ello que, a veces, se dice que los científicos juegan a ser Dios.

\section{Cuadro 2: Las técnicas de fertilización asistida como producción indus- trial}

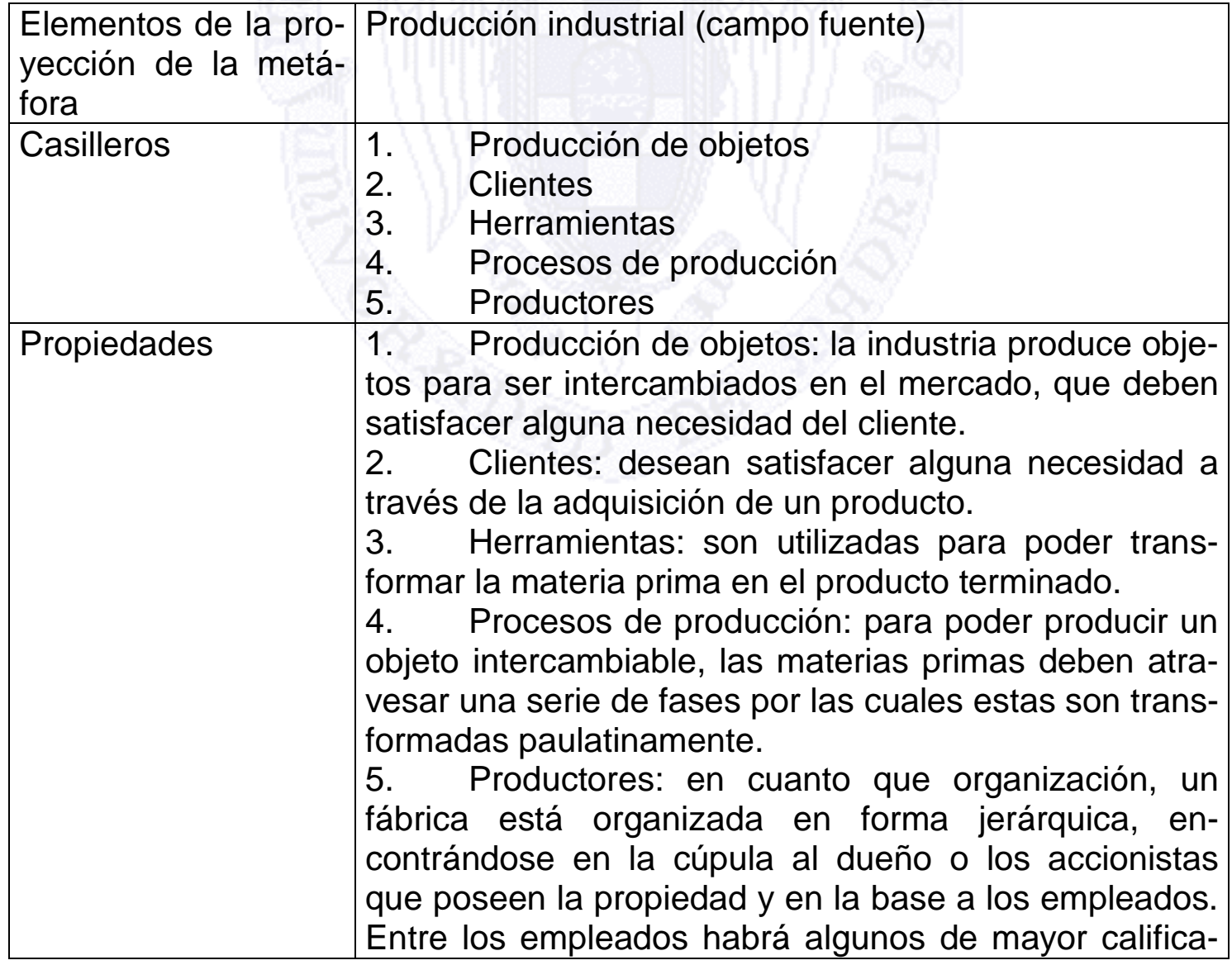

${ }^{12}$ La cursiva pertenece al texto original. 


\begin{tabular}{|l|l|}
\hline Relaciones & $\begin{array}{l}\text { ción, encargados de diseñar o proyectar el producto, } \\
\text { otros encargados de seleccionar la mejor estrategia de } \\
\text { venta y otros que aplicarán su fuerza física y mental } \\
\text { para producir el objeto. }\end{array}$ \\
\hline Saberes & $\begin{array}{l}\text { El mercado es el lugar en el que el cliente y el produc- } \\
\text { tor (o sus mediadores) se encuentran para realizar el } \\
\text { intercambio entre producto y dinero. }\end{array}$ \\
$\begin{array}{l}\text { 1. Los productos tienen diferentes grados de sofis- } \\
\text { ticación y durabilidad. } \\
2 . \quad \text { Algunos productos pueden tener defectos de } \\
\text { fabricación, con lo cual se hace necesario sustituirlos o } \\
\text { descartarlos. } \\
\text { 3. Se suele considerar que la sociedad actual es } \\
\text { una sociedad donde todo es descartable ("the throw- } \\
\text { away society"), de manera que la relación del hombre } \\
\text { con las cosas se hace crecientemente temporal. Los } \\
\text { objetos forman parte de la estructura de las situacio- } \\
\text { nes, con lo cual un acortamiento de la relación con los } \\
\text { objetos redunda en una aceleración del ritmo de vida. } \\
\text { (Toffler, 1970). } \\
4 . \quad \text { La industria pretende escuchar al cliente, para } \\
\text { saber qué es lo que desea, al tiempo que, a través del } \\
\text { marketing, se intenta generar necesidades en el clien- } \\
\text { ter. }\end{array}$ \\
\hline
\end{tabular}

\begin{tabular}{|c|c|}
\hline $\begin{array}{l}\text { Propiedades proyec- } \\
\text { tadas de la produc- } \\
\text { ción industrial }\end{array}$ & $\begin{array}{l}\text { 1. Producción de objetos: los productos pueden ser } \\
\text { para el consumo inmediato o ser bienes durables. } \\
2 . \quad \text { Clientes: seleccionan, de entre la oferta, cuál es } \\
\text { el producto que más les conviene, o, en algunos casos, } \\
\text { pueden pedir que se produzca un objeto según sus } \\
\text { deseos. } \\
\text { 3. Procesos de producción: transforman la materia } \\
\text { prima en el objeto terminado. Ellos pueden implicar la } \\
\text { utilización de maquinaria muy sofisticada. } \\
4 . \quad \text { Productores: constituyen un estrato en la jerar- } \\
\text { quía interna de la empresa, y son los encargados de } \\
\text { planificar y llevar a cabo la producción de la mercancía. }\end{array}$ \\
\hline $\begin{array}{l}\text { Propiedades que se } \\
\text { le asignan a la fertili- } \\
\text { zación asistida }\end{array}$ & $\begin{array}{l}\text { 1. Producción de objetos: los seres nacidos por } \\
\text { estos procedimientos son producidos obedeciendo cier- } \\
\text { tos estándares de calidad. En el caso del uso terapéu- } \\
\text { tico de embriones, estos se volverán "descartables", } \\
\text { luego de utilizados, puesto que su ciclo de consumo se } \\
\text { encontraría terminado. Mientras que la producción de } \\
\text { un hijo implicaría que éste es tratado como un bien du- } \\
\text { rable, además de que la selección de embriones con- } \\
\text { duciría hacia el eugenismo. } \\
2 \text {. Clientes: son los padres que desean tener un } \\
\text { hijo, o los pacientes que aguardan una terapia con } \\
\text { células provenientes de embriones. } \\
3 . \quad \text { Procesos de producción: las células de los do- }\end{array}$ \\
\hline
\end{tabular}




\begin{tabular}{|l|l|}
\hline nantes deben ser "manipuladas" cuidadosamente para \\
poder lograr los resultados deseados. Para ello se ne- \\
cesitará de la más sofisticada tecnología. \\
$4 . \quad$ Productores: en este caso, serán los científicos \\
encargados de diseñar, planificar y ejecutar todo el \\
proceso de producción del embrión, desde la extrac- \\
ción de las células de los donantes, hasta su implanta- \\
ción, control de embarazo, etc.
\end{tabular}

El cuadro muestra como, de la milagrosa unión amorosa entre los padres, la concepción pasa a ser un proceso social de producción, donde, entre medio de la pareja, aparecen una serie de personajes, o directamente, enteras organizaciones especializadas en la "producción" de embarazos. Por otra parte, esta metáfora da paso a la última categoría, que son las figuras eugenésicas. En relación con esto, no es casual que se cite tanto a la famosa novela de Huxley, Un mundo feliz (Ferrer, 1995); (Rabinovich-Berkman, 2005); (Parise, 2007), donde se habla de fecundación in vitro en úteros artificiales. Además, el eugenismo tiende a invocar el recuerdo del nazismo, llevando a pensar que el mundo se acercaría hacia una nueva forma de régimen totalitario, similar al Estado comandado por Hitler o al representado por el mencionado novelista inglés. Asimismo, el eugenismo implica la idea de selección, cosa que no permitía la reproducción sexual "natural", situación que podía ser asimilada la voluntad divina o a la casualidad, o sea, a fuerzas incontrolables por la voluntad humana. Por consiguiente, quedaría en manos de padres y médicos la posibilidad de seleccionar, según sus gustos, los embriones que deseen, eliminando el resto. De más estaría aclarar por qué tal idea es asociada al nazismo.

\section{Problemas éticos y jurídicos de la manipulación de embriones}

Uno de los tópicos bioéticos a los que más se recurre ante este tipo de problemas es a la dignidad humana ${ }^{13}$. Algunos sostienen que la fecundación in vitro es violatoria de este principio, debido a que el ser humano "merece ser concebido en un acto dialogal unitivo, expresivo del amor del padre y la madre" (Basset, 2009). Aunque, en este mismo texto se señala que la dignidad de los embriones restantes o supernumerarios se encuentra más afectada, "porque les depara un destino que es indigno de un ser humano: una heladera". En relación con esto último, se llega a señalar los posibles daños que podría ocasionar la congelación y descongelación en la estructura del embrión, alcanzándose a hablar de las posibles "consecuencias psíquicas" que podría tener esta condición en las futuras etapas de la vida de este ser humano (Lafferriere, 2006). Parece cuanto menos exagerado hablar de posibles daños psíquicos, cuando, en muchos casos, en estos embriones, ni siquiera se pueden distinguir desarrollos de su sistema nervioso central. Para otros, se estaría violando el derecho a la dignidad, debido a que -invocando la fórmula kantiana- el hombre es siempre un fin en sí mismo y no "una cosa sujeta a la voluntad de otros" (Casanova, 2005). Otros autores señalan que el simple hecho de seleccionar algunos de

${ }^{13}$ Debido a la extensión del trabajo es imposible realizar caracterizar este complejo concepto y su evolución. 
los óvulos fecundados, dejando de lado otros, ya significaría un atentado contra la dignidad de la persona, más allá del criterio utilizado para tal selección (Cocca, 1994). En relación con esto último es que aparecen voces alarmadas por la aparición de un posible "eugenismo discriminatorio" (Basset, 2009).

Otro de los problemas éticos expuestos en los textos, indica que, en el caso de la fecundación heteróloga (donde se usan gametos de donantes anónimos), se estaría violando el derecho a la identidad, ya que toda persona tiene el derecho a conocer su origen (Casanova, 2005). En oposición a todo lo antes expuesto, comentando el fallo que terminó por prohibir la "píldora del día después", se discute que el derecho a la vida sea siempre a considerar como un derecho "absoluto" (Basterra, 2002), sin tener en cuenta los otros derechos en juego en tal resolución. En tal sentido, la autora reivindica el derecho a la autonomía, la libertad e intimidad, a la salud reproductiva y la concepción responsable. Como estrategia retórica, en el texto se entabla una relación entre el principio éticojurídico de autonomía y una sociedad pluralista, llegando a estas conclusiones:

Si adscribimos al principio de autonomía personal, tendremos una sociedad pluralista, en la que pueda convivir aquella persona que decide no ingerir una píldora de anticoncepción de emergencia, puesto que su conciencia y/o la religión a la que adscriben no se lo permite, y ha decidido vivir con la concepción de que el derecho a la vida es "absoluto" y, siempre cede ante cualquier otro valor en juego, lo que consideramos sumamente valioso. Pero también permite que aquella persona que así lo considere, pueda hacer uso de la misma (píldora) por que ha elegido vivir ejerciendo plenamente otros derechos humanos básicos que igualmente tienen jerarquía constitucional como los derechos reproductivos y sexuales, libres de coacción y violencia, como, especialmente a decidir en forma responsable sobre la procreación, el número de hijos y el intervalo entre sus nacimientos; o el derecho a la autodeterminación procreativa de los padres o de la mujer.

Pese a que esta posición pueda ser bioéticamente sostenible, no termina por explicitar qué posición debería asumirse frente al embrión y cómo debería revertirse la tradición interpretativa desarrollada por la jurisprudencia.

\section{Conclusiones}

Como se ha mostrado a lo largo del trabajo, tanto el sistema del derecho, como el sistema político, en la Argentina, han interpretado las problemáticas relacionadas con el embrión de manera idéntica. Solamente en algún artículo de doctrina se ha planteado alguna duda respecto de la visión hegemónica, que entiende al embrión como una persona, desde el primer instante de su vida, o sea, desde la fecundación: cuando el espermatozoide penetra en el óvulo. Esto contrasta claramente con la situación de algunos países europeos, donde se cuenta con legislación desde hace varios años y donde el debate ha sido y sigue siendo un tema controversial. De esta manera, todo tipo de experimentación y manipulación de los mismos estaría inmediatamente prohibida. En este sentido, muchos juristas plantean velada o directamente la necesidad de limitar o prohibir los métodos de fecundación in vitro, puesto que la eliminación o congelación de los embriones iría en contra de su derecho a la vida, al tiempo que 
su baja efectividad implicaría un sacrificio inútil. En esta misma línea de pensamiento, se identificaron algunos proyectos de ley que, debido a las numerosas cláusulas que promueven, parecen estar encaminados a hacer todo lo posible para que se desista de emplear estas técnicas.

La identificación de tres clases de metáforas recurrentes, sobre todo, en la doctrina, permite observar la estrategia retórica desarrollada en pos de consolidar la postura jurídica antes delineada. Por consiguiente, una de los expedientes es humanizar al embrión, tratándolo como si fuera ya un niño y viendo al conjunto de embriones como una comunidad de hermanos. De esta manera, se toma como un hecho, o se lo quiere hacer pasar como tal, que el embrión es una persona. Los otros dos grupos de metáforas funcionan en sentido contrario, intentando desacreditar a los métodos de fertilización in vitro. Ellos consisten en tratar a estas técnicas como una producción industrial y como una forma de eugenesia. De esta manera, lo que se está mentando es que tales tratamientos son deshumanizantes y desacralizan la vida humana. En este sentido, algunos juristas entienden que, a través de estos procedimientos, se estaría ofendiendo la dignidad humana, por tratar a los embriones como meros medios, o por no darles la oportunidad de ser el resultado de una relación amorosa entre los padres. Por otra parte, en el caso de la fecundación heteróloga específicamente, además, se estaría violando el derecho a la identidad.

\section{Bibliografía}

- (1998) ARNOLD, M., "Recursos para la investigación sistémico / constructivista", Cinta de Moebio, No.3, abril, <http://www.moebio.uchile.cl/03/frprin05.htm>.

- (2004) CALSAMIGLIA, H. y T. VAN DIJK, "Popularization discourse and knowledge about the genome", Discourse and society, 15 (4), pp.369-389.

- (2005) GLASNER, P., "Banking on Immortality? Exploring the Stem Cell Supply Chain from Embryo to Therapeutic Application", Current Sociology, 53(2), pp.355-366.

- (2008) HENNETTE-VAUCHEZ, S., "Words count. How interest in stem cells has made the embryo available: a look at the French law of bioethics", EUI Working Papers LAW, 2008 (19), <http://ssrn.com/abstract=1303997>.

- (1999) KIREJCZYK, M., "Parliamentary Cultures and Human Embryos: The Dutch and British Debates Compared", Social Studies of Science, 29 (6), pp.889-912.

- (2007) KRUVAND, M. y S. HWANG, "From Revered to Reviled: A CrossCultural Narrative Analysis of the South Korean Cloning Scandal", Science Communication, 29 (2), pp.177-197.

- (1989) LAKOFF, G. y M. TURNER, More than cool reason, University of Chicago Press, Londres.

- (2003) LAKOFF, G. y M. JOHNSON, Metaphors we live by, University of Chicago Press, Londres.

- (1993) LUHMANN, N., Das Recht der Gesellschaft, Suhrkamp Verlag, Frankfurt a.M.

- (2006) _ _ _ El derecho de la sociedad, Herder, Barcelona. 
- (2008) MAESEELE, P. y D. Schuurman, "Biotechnology and the Popular Press in Northern Belgium: A Case Study of Hegemonic Media Discourses and the Interpretive Struggle", Science Communication, 29 (4), pp.435-471.

- (2002) MCCLOSKEY, B., "The Controversy Surrounding Stem Cell Research", Policy, Politics, \& Nursing Practice, 3(1), pp.4-13.

- $\quad$ (1993) MULKAY, M., "Rhetorics of Hope and Fear in the Great Embryo Debate", Social Studies of Science, 23, pp.721-742.

- (1994a) _ _ _Science and Family in the Great Embryo Debate", Sociology, 28 (3), pp.699-715.

- (1994b) _ _ "The Triumph of the Pre-Embryo: Interpretations of the Human Embryo in Parliamentary Debate over Embryo Research", Social Studies of Science, 24, pp.611-639.

- _ (1995a) _ _ _Galileo and the Embryos: Religion and Science in Parliamentary Debate over Research on Human Embryos", Social Studies of Science, 25, pp.499-532.

- $\quad$ (1995b) ___ "Parliamentary Ambivalence in Relation to Embryo Research", Social Studies of Science, 25, pp.149-163.

- (2002) NISBET, M. y B. LEWENSTEIN, "Biotechnology and the American Media: The Policy Process and the Elite Press, 1970 to 1999", Science Communication, 23 (4), pp.359-391.

- (2003) NISBET, M., D. BROSSARD y A. KROEPSCH, "Framing Science: The Stem Cell Controversy in an Age of Press/Politics", The Harvard International Journal of Press/Politics, 8, pp.36-70.

- (2008) PARDO, R. y F. CALVO, "Attitudes Toward Embryo Research, Worldviews, and the Moral Status of the Embryo Frame", Science Communication, 30(1), pp.8-47.

- (2003) PARRY, S., "The politics of cloning: mapping the rhetorical convergence of embryos and stem cells in parliamentary debates", New genetics and society, 22(2), pp.145-168.

- $\quad$ (1997) ROSS, A., Sobre el derecho y la justicia, Eudeba, Buenos Aires.

- (1987) SOLER, S., Derecho penal argentino, Tomo I, TEA, Buenos Aires.

- (2008) SVENDSEN, M. y L. KOCH, "Unpacking the 'Spare Embryo': Facilitating Stem Cell Research in a Moral Landscape", Social Studies of Science, 38 (1), pp.93-110.

- $\quad$ (1970) TOFFLER, A., Future shock, Random House, Nueva York.

- (2003) WILLIAMS, C., J. KITZINGER y L. HENDERSON, "Envisaging the embryo in stem cell research: rhetorical strategies and media reporting of the ethical debates", Sociology of health and illness, 25(7), pp.793-814.

\section{Anexo: Artículos de doctrina analizados}

Los siguientes artículos han sido tomados de la editorial Abeledo Perrot (http://www.abeledoperrot.com/). En el citado se sigue la forma utilizada por la editorial:

- (2009) BASSET, Úrsula C., "Un bebé ¿puede ser un medicamento? Reparos ético-jurídicos a un fallo que sienta buenos principios y deriva en malas 
conclusiones", Lexis No 0003/014504 ó 0003/014507 ó 0003/014506, SJA 10/6/2009.

- (2002) BASTERRA, Marcela, "Prohibición de la píldora del 'día después'; un lamentable retroceso del principio de autonomía personal", RDF 2002-21198.

- (1995) Ferrer, Francisco A. M., "El embrión humano y la nueva Constitución", Lexis No 0003/001914 ó 0003/001967 ó 0003/001952, JA 1995-II-855.

- (1998) LOYARTE, Dolores, "Adopción prenatal: Reflexiones sobre un proyecto de ley", Lexis No 0003/000488, JA 1998-III-964.

- (2000) LOYARTE, Dolores y ROTONDA, Adriana E., "Protección de la vida humana extrauterina: aciertos de los primeros precedentes judiciales argentinos. La tutela del valor "vida", los legitimados por intereses difusos y la vía del amparo", Lexis No 0003/007764 ó 0003/007785 ó 0003/007689 ó 0003/007684, JA 2000-III-641.

- $\quad$ (2005) PALACIOS, Marcelo, "Ley sobre Técnicas de Reproducción Asistida 35/1988. De 1988 a 2005", Lexis No 0003/012171 ó 0003/012199 ó 0003/012185, SJA 28/9/2005 - JA 2005-III1269.

- (2006) PERRINO, Oscar, Derecho de familia.

- (2009) ROSALES, Pablo O., "Fertilización humana asistida: una discusión jurídica que recién comienza", Lexis No 0003/800726, APBA 2009-7-769.

Los siguientes artículos han sido tomados de la editorial El Derecho (http://www.elderecho.com.ar/). En el citado se sigue la forma utilizada por la editorial:

- (2008) ANDÚJAR DE ZAMORA, Miryan, "El valor de la vida de la persona por nacer", EDCrim, (07/07/2008, nro. 12.043)

- (2001) ARIAS DE RONCHIETTO, Catalina Elsa, "Filiación por dación del embrión crioconservado - Censar y legislar: cuestión imperativa del derecho nacional", ED, 193-667.

- (2005) BARBIERI, Javier H., "La técnica de reproducción asistida FIVET atenta contra la vida humana", EDCrim, (08/09/2005, nro. 11.338)

- $\quad$ (2008) BASSET, Ursula C., "En el estado de derecho, la tutela de la vida no admite excepciones", ED, 229-698.

- (2005) CASANOVA, María Paula, "Embriones congelados y temas conexos", EDCrim, (08/09/2005, nro. 11.338)

- (2005) ERRÁZQUIN, Alicia, "Acerca del conocimiento del más pequeño ser humano", EDCrim, (08/09/2005, nro. 11.338)

- (2006) ERRÁZQUIN, Alicia, "Descubriendo en el embrión a uno de nosotros", EDCrim, (21/09/2006, nro. 11.598)

- (2006) LAFFERRIERE, Jorge Nicolás, "Técnicas de procreación humana. Propuesta para la tutela legislativa de la persona concebida (Honorable Senado de la Nación. Comisiones de "Salud y Deporte", "Legislación General" y "Justicia y Asuntos Penales". Audiencia sobre "Fertilización asistida: Aspectos Jurídicos", Buenos Aires, 15 de agosto de 2006)" - [ED, 219-858]

- (2001) MADRID RAMIREZ, Raúl, "Consideraciones sobre la personalidad del embrión humano", ED, 192-894. 
- (2009) QUINTANA, Eduardo Martín, "El costo jurídico de un 'niño de diseño': ¿seres humanos más humanos que otros?", ED, (09/06/2009, nro. 12.271)

Los siguientes artículos han sido tomados de la editorial La Ley (http://www.laleyonline.com.ar/maf/app/authentication/formLogin). En el citado se sigue la forma utilizada por la editorial:

- (2005) ARRIBERE, Roberto, "Improcedencia e inconveniencia de la designación de un tutor especial a los prembriones criopreservados", Sup.Act 10/11/2005, 1-Sup.Act 08/11/2005, 1.

- (1996)BARRA, Rodolfo C., "Embriones expósitos", LA LEY 1996-D, 1271.

- (1997) BLANCO, Luis Guillermo, "Consideraciones acerca de la investigación y experimentación biomédica en embriones y fetos humanos vivos no viables - Apostillas acerca de una sentencia del tribunal constitucional de España", LA LEY 1997-D, 190.

- (1984) COCCA, Aldo Armando, "Nacer con dignidad (Manipulación del embrión humano)", LA LEY 1984-C, 1127.

- (2009) KRASNOW, Adriana N., "Procreación humana asistida. Crear una vida para salvar otra vida", LLBA 2009 (abril), 251.

- (2009) NALLAR, Florencia, "Destino de los embriones crioconservados", LA LEY 2009-B, 296.

- (2007) PARISE, Agustín, "El status legal de los embriones humanos en la jurisprudencia de los Estados Unidos de América”, LA LEY 2007-F, 1088.

- (2005) RABINOVICH-BERKMAN, Ricardo D., "La tutela de los embriones congelados", LA LEY 2005-E, 1152. 